\title{
PATHOLOGY OF AN APHAKIC EYE CONTAINING AN ANTERIOR CHAMBER IMPLANT*
}

\author{
BY \\ N. ASHTON \\ Department of Pathology, Institute of Ophthalmology, University of London \\ AND \\ J. BOBERG-ANS \\ Private Ophthalmic Practice, Copenhagen, Denmark
}

ONLY two pathological examinations of human eyes containing acrylic implants have so far been reported (Ashton and Choyce, 1959; Manschotsee Binkhorst, 1959). A third case is here described.

\section{Case Report}

A man aged 67 years presented with cataract in both eyes. A nuclear cataract had been present in the left eye for some time and this annoyed him, especially when driving at night. There was no history of other illness. In September, 1959, an intracapsular cataract extraction of the left eye was performed. The cataract was extracted through a $180^{\circ}$ von Graefe incision, preserving a large conjunctival flap. Sutures at 10 and 12 o'clock were inserted before the extraction. Peripheral iridotomy at 10 o'clock was performed and alpha-chymotrypsin (Maw preparation) was allowed to act for 2 minutes. A further five virgin silk sutures were inserted subconjunctivally, a continuous suture was placed in the conjunctiva, and air was injected into the anterior chamber. No post-operative complications developed and the visual acuity of the left eye 3 weeks later was 1.0 with $+12 \mathrm{D}$ sph., $1.5 \mathrm{D}$ cyl., axis $150^{\circ}$, with a vertex distance of $14 \mathrm{~mm}$. in the trial frame and a diameter of the anterior chamber of $13.5 \mathrm{~mm}$. The visual acuity of the right eye was 1.0 with $+3.5 \mathrm{D}$ sph.

On February 22, 1960, a semi-rigid, fenestrated, 13-mm. lens $\dagger$ was inserted into the anterior chamber of the left eye. The eye was opened through a 6-mm. limbal incision with a keratome from 2 to 5 o'clock. A 12-mm. lens was tried first but was found to be too short so was replaced by a 13-mm. lens. The lens rested with its point at 8 o'clock and its base at about 1 to 3 o'clock. Uneventful recovery with a final visual acuity 20 days later of 1.0 with $-1 \mathrm{D}$ sph., $-2.5 \mathrm{D}$ cyl., axis $60^{\circ}$. The patient was satisfied and wore bifocal spectacles with comfort. He now drove his car without difficulty.

Unfortunately the patient was taken ill a month later with gastric symptoms and died from a malignant tumour of the stomach on August 8, 1960, about $5 \frac{1}{2}$ months after the operation. The eye was enucleated 10 hours after death, fixed in formol saline, and sent for pathological examination.

* Received for publication February 27, 1961

† Boberg design, made by Rayner, Bond Street, London, W.1. 


\section{Pathological Examination}

The eye was opened antero-posteriorly in an oblique line from 1 to 9 o'clock as shown in the diagram (Fig. 1, Level A). The small upper nasal portion containing seven silk sutures was sectioned serially in paraffin wax. The main portion containing the lens implant was photographed and then immersed in chloroform to dissolve the lenticulus and was finally sectioned serially in celloidin.

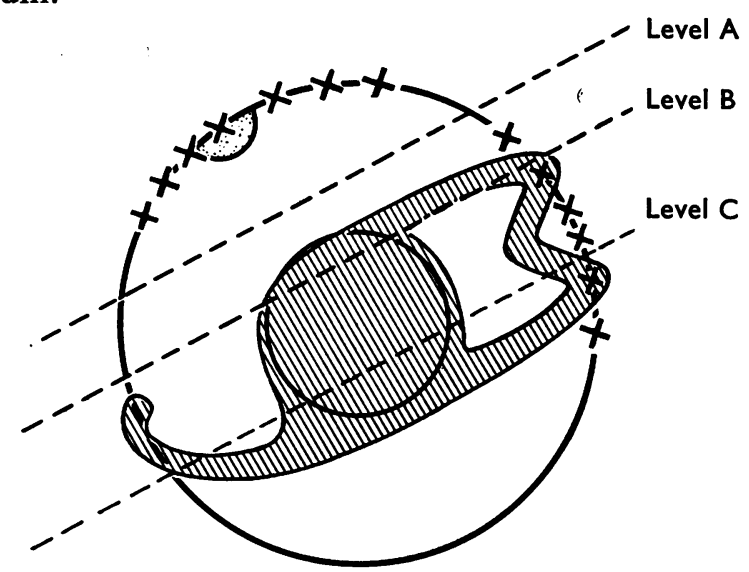

FIG. 1.-Diagram showing implant in situ and three levels at which sections are described.

\section{Macroscopic Examination}

The opened eye showed no lens remnants. A small quantity of opalescent fluffy material could be seen behind the iris in the region of the ciliary body and in the posterior polar region of the fundus. A posterior view of the iris showed that the haptic portions of the bipolar end of the implant had displaced the iris backwards to form two pockets of such depth as to obscure the ciliary processes at these points. There was no such backward protrusion of iris tissue on the opposite side.

\section{Microscopic Examination}

Paraffin Wax Sections of the Upper Nasal Cap at level "A" showed two oblique operation wounds perforating the cornea on either side; these were almost perfectly aligned and had healed with a minimum of scar tissue (Fig. 2, opposite).

In some sections fragments of silk suture could be seen adjacent to one of the wounds, and around this material there was only a slight reaction consisting of a few lymphocytes, plasma cells, and an occasional giant cell (Fig. 3, opposite). No eosinophils were seen. In addition to the wounds the cornea showed a mild inflammatory infiltration at the limbus and some vacuolation in the corneal endothelium. The corneo-iridic angle, trabecular meshwork, and Schlemm's canal were entirely normal. Similarly, apart 


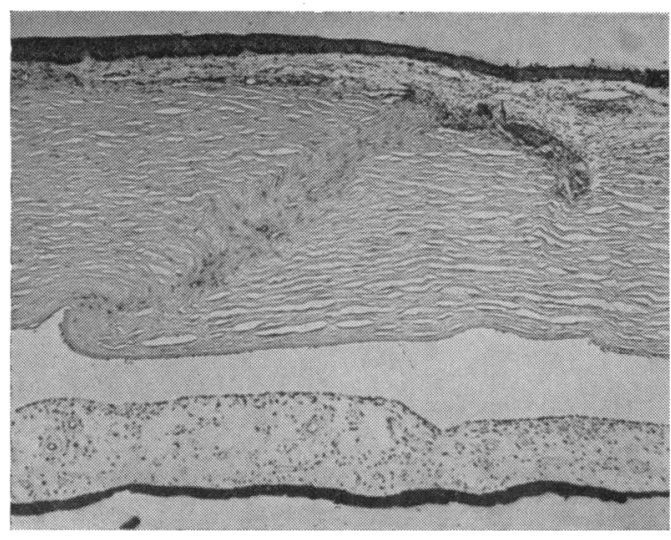

FIG. 2.-One of the oblique operation wounds at level "A" showing satisfactory healing. Paraffin wax section. Haematoxylin and eosin. $\times 32$.

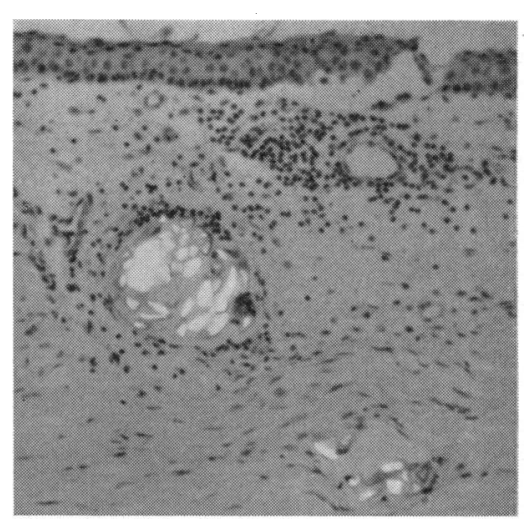

Fig. 3.-Fragment of silk suture adjacent to one of the wounds. Note that there is only slight inflammatory reaction. Paraffin wax section. Haematoxylin and eosin. Polarized light. $\times 113$.

from iridotomy, there was no abnormality in the iris, and the severed free edges of the iridotomy showed no inflammatory or other tissue reaction. Early hyalinization of the ciliary body was present, but the remainder of this portion of the eye was histologically normal.

Celloidin Sections at Level " $B$ " showed the distortion caused by the upper haptic portion of the bipolar end of the lenticulus; here the iris root was acutely retroverted to form an angular pocket in which the foot of the lenticulus rested. Laterally the retroverted iris was opposed to the ciliary body, which it overlapped entirely, and was adherent to it through delicate hyaline adhesions containing migrated iris pigment. Some proliferation of the ciliary epithelium had occurred. The filtration angle on this side was patent, but the trabecular meshwork showed some collapse with cellular and pigment infiltration. On this side also a healed linear perforating wound could be seen in the limbal region, which was otherwise normal.

The retroverted iris root forming the pocket of the implant was remarkably normal in appearance, showing only slight thinning and no fibrosis or inflammatory reaction. On the other hand, the inner two-thirds of the iris, which presumably brushed against the lenticulus in life, showed a pronounced fibroblastic reaction on the most prominent parts of its surface; into these areas pigment had migrated and there was a mild inflammatory infiltration throughout the iris stroma. No eosinophils were seen. The pigment layer of the iris was detached, probably as a result of post mortem degeneration, especially as the retina showed advanced autolytic changes in all its layers. One or two macrophages could be seen in the anterior vitreous and on the surface of the retina, but there was no evidence of any inflammatory reaction in the ciliary body, choroid, or retina. The other 
filtration angle showed no abnormality, apart from increased pigmentation of the trabecular meshwork. No remnants of the crystalline lens were seen.

Celloidin Sections at Level "C" (Fig. 4) also showed the gross distortion caused by the bipolar haptic portion of the lenticulus. The iris was still acutely retroverted and angulated with some atrophy and pigmentary disturbance at its root. The linear limbal wound could also be seen at this level,

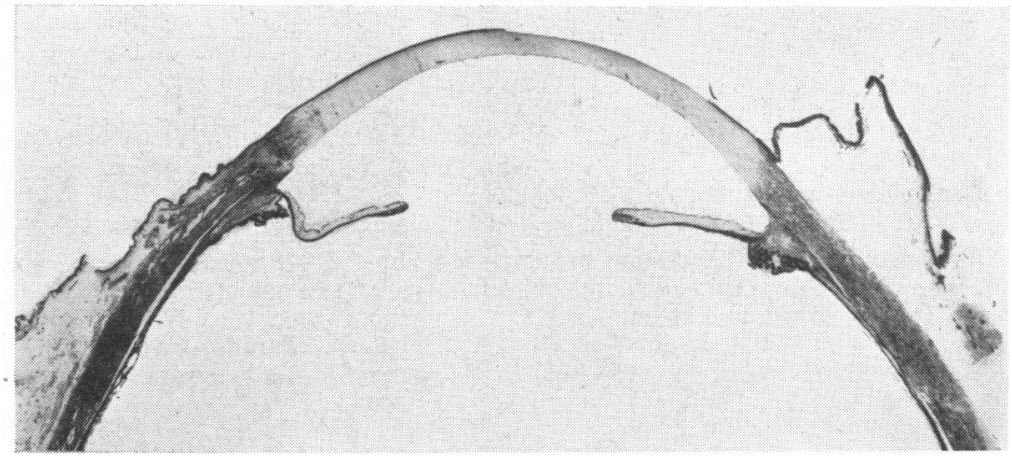

FIG. 4.-Anterior segment at level " $\mathrm{C}$ " showing distortion of the angles and the iris caused by the implant. Celloidin section. Haematoxylin and eosin. $\times 5$.

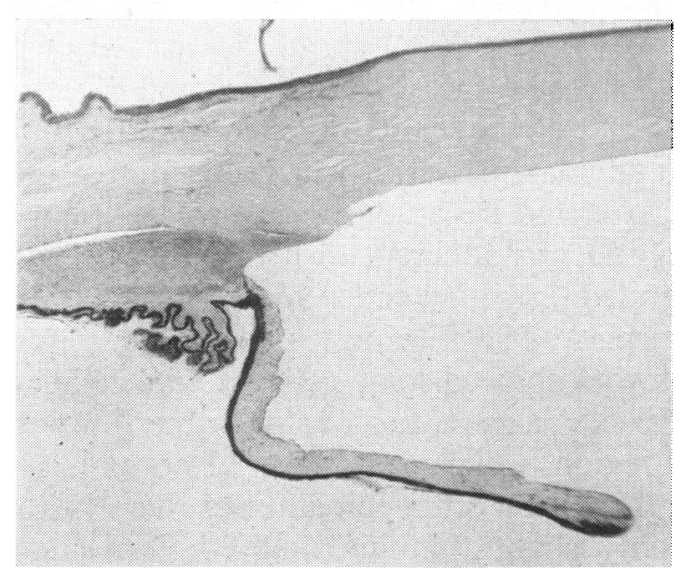

FIG. 5.-Higher-power view of the upper angle appearing on the left in Fig. 4. Note the angulation and acute retroversion of the iris to form a bed for the upper haptic portion of the implant. The trabeculae and Schlemm's canal are normal; the linear operation wound can be seen nearby. There is marked atrophy and pigmentary disturbance at the iris root. $\times 15$.

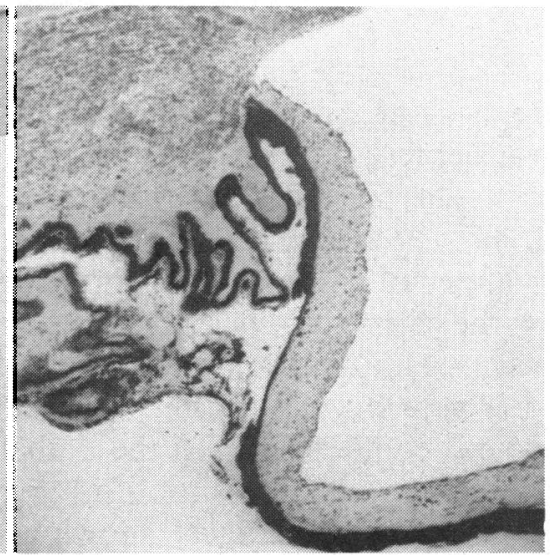

FIG. 6.-High-power view of Fig. 5 showing pigmentary disturbance of the iris and ciliary body, and the attenuated iris root, with delicate adhesions between the iris and ciliary body. $\times 34$.

being well healed and perfectly aligned, while the adjacent filtration angle, apart from a slightly increased cellularity in the meshwork, was widely patent (Figs 5 and 6). The opposite filtration angle on the other side showed the distortion caused by the unipolar haptic portion of the lenticulus 
which was considerably less than on the other side; the corneo-iridic angle had widened through forward displacement of the meshwork, lateral displacement of the ciliary body, and backward displacement of the iris root which was markedly atrophic. In the adjacent tissues only a very mild reaction, consisting of a few scattered lymphocytes, could be seen; no eosinophils or giant cells were found (Figs 7 and 8). The remaining part of the iris on this side showed little abnormality apart from slight atrophy and some pigmentary disturbance of the pupil; in fact the iris generally was remarkably free from inflammatory infiltration. The other notable features at this level of section were the presence of retinal oedema, a cluster of cytoid bodies in the inner retina above the disc (Fig. 9), and a single cluster

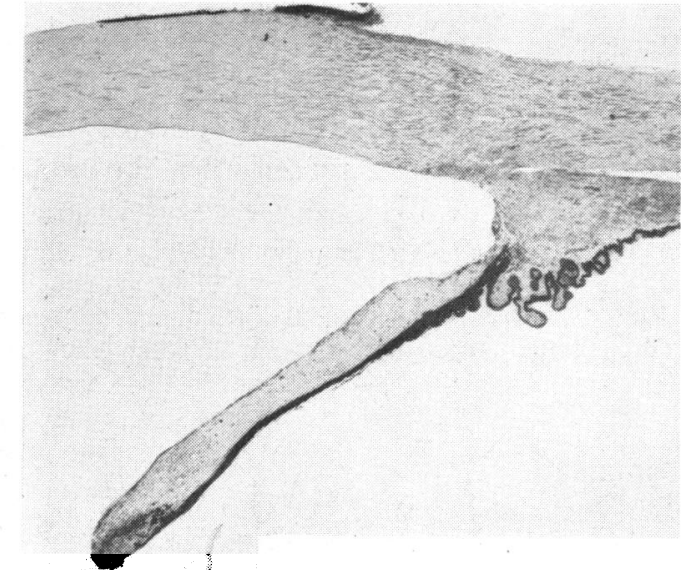

FIG. 7.-Higher-power view of the opposite angle showing widening through compression of the meshwork, ciliary body, and iris root. $\times 15$.

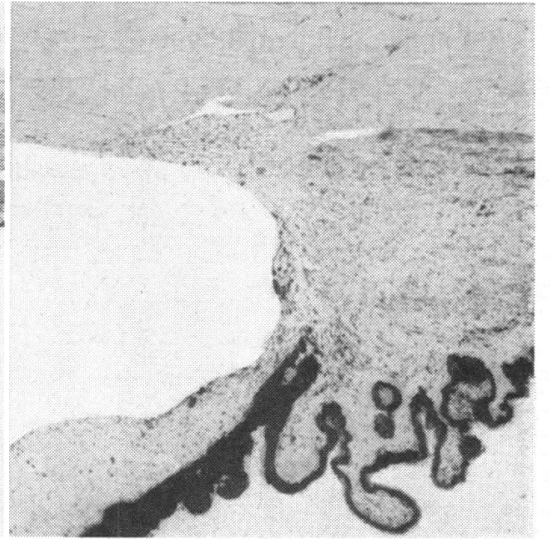

FIG. 8.-High-power view of Fig. 7 showing atrophy of the iris root and the very mild inflammatory reaction in the adjacent tissues. $\times 34$.

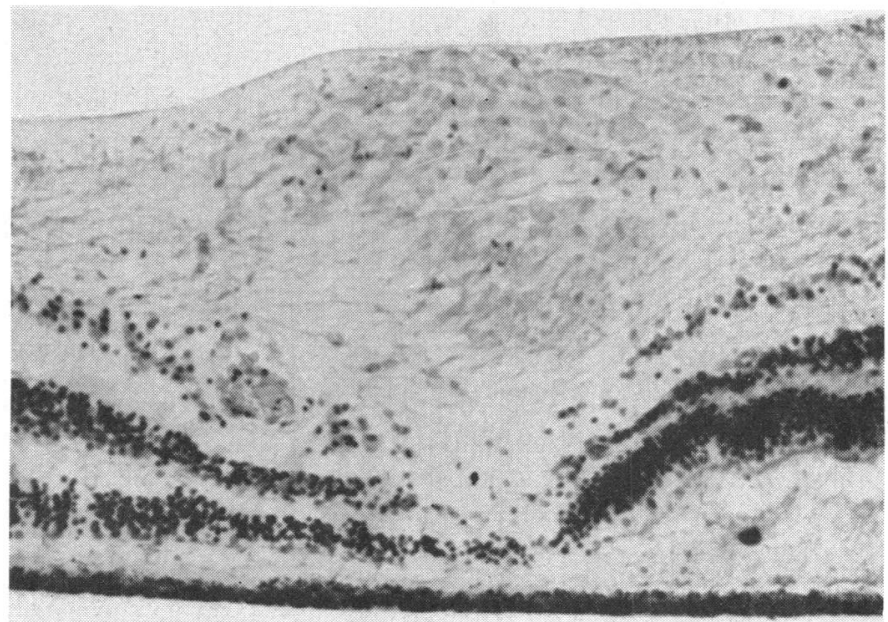

FIG. 9.-Cluster of cytoid bodies seen in the retina above the disc. Haematoxylin and eosin. $\times 170$. 
of inflammatory cells at the margin of the disc. As in the previous sections the retina showed considerable post mortem autolysis.

\section{Summary of Findings}

(1) There was satisfactory healing of corneal wounds with very little reaction around the silk sutures which were still present. No other corneal abnormality was seen.

(2) The distortion caused by the lenticulus was considerably more pronounced at the bipolar haptic end, where the iris was acutely retroverted and adherent to the ciliary body, than at the unipolar end, where only widening of the angle had occurred.

(3) The inflammatory reaction to the implant was extremely slight and there was no evidence of hypersensitivity to the acrylic material. There was in general only a moderate degree of atrophy at the iris root on both sides where the acrylic lens rested, and a fibroblastic reaction on the most prominent parts of the iris surface. The filtration angles were patent and, apart from a slight increase in pigmentation, the trabecular meshwork was healthy.

(4) There was some oedema of the retina and one focus of cytoid bodies was present near the disc.

\section{Comment}

It would seem likely that the retinal oedema and cytoid bodies were caused by the patient's terminal illness; such lesions have in fact been reported in carcinoma of the stomach (Kiewe and Hart, 1951) and are probably due to anaemia. The changes relevant to the implant are thus confined to the anterior segment and show that the only significant consequences were distortion and atrophy of the iris roots adjacent to the haptic portions of the acrylic lens, for the inflammatory response to the implant was so slight as to be negligible and there was no evidence of any sympathetic or foreignbody type of reactions.

It is interesting to compare this case, in which the implant had been present for $5 \frac{1}{2}$ months, with that of Ashton and Choyce (1959), in which the implant had been present for only 6 weeks, and to answer some of the questions they raised. The degree of atrophy in the supporting iris tissue was less than in their case, which somewhat allays the fear they expressed that progressive atrophy might in time result in dislocation or displacement of the implant. This, however, is still a possible complication to be taken into account, for as can be seen in our illustrations the attenuated iris roots provide only a very delicate sling for the lenticulus. The threat of glaucoma from inflammatory or sclerotic processes, which Ashton and Choyce could not exclude in their case after so short a time, now seems more remote in that there was 
no sign of either in our case. Lastly, in contrast to the finding of Ashton and Choyce, there was no evidence of macular oedema and it may be fairly confidently concluded that this was not a complication of the lens implant per se.

\section{Summary}

The histopathological examination of a human eye containing an anterior chamber implant is reported and the findings are discussed.

We should like to thank Messrs. G. E. Knight and V. Elwood for their technical assistance and Miss E. FitzGerald for secretarial help.

\section{REFERENCES}

Ashton, N., and CHOYCE, D. P. (1959). Brit. J. Ophthal., 43, 577.

KIEWE, P. L., and HART, F. DUDLEY (1951). Trans. ophthal. Soc. U.K., 71, 309.

MANSCHOt, W. A. (1959). See BINKHORST, C. D. (1959). Klin. Mbl. Augenheilk., 134, 536 (Fig. 6 on p. 539). 